\title{
A sex-linked Ace gene, not linked to insensitive acetylcholinesterase-mediated insecticide resistance in Culex pipiens*
}

\author{
C. A. Malcolm, ${ }^{1}$ D. Bourguet, ${ }^{2} \dagger$ A. Ascolillo, ${ }^{1}$ \\ S. J. Rooker, ${ }^{1}+$ C. F. Garvey, ${ }^{1}$ L. M. C. Hall, ${ }^{3}$ \\ N. Pasteur ${ }^{2}$ and M. Raymond ${ }^{2}$ \\ ${ }^{1}$ School of Biological Sciences, Queen Mary and \\ Westfield College, University of London, London, UK, \\ 2 Institut des Sciences de l'Evolution (UMR 5554), \\ Laboratoire Génétique et Environnement, Université \\ Montpellier II (C.C. 065), Montpellier, France, and \\ ${ }^{3}$ Department of Medical Microbiology, London Hospital \\ Medical College, University of London, London, UK
}

\begin{abstract}
An acetylcholinesterase (AChE) gene, Ace.x, showing $93 \%$ identity of deduced amino acid sequence to Anopheles stephensi Ace has been cloned from a Culex pipiens strain homozygous for insensitive AChE (iAChE) mediated insecticide resistance. DNA sequence of genomic DNA clones identified exons 2-5. RFLP of six clones indicated four possible alleles. Linkage analysis located Ace.x to chromosome I, less than 0.8 centimorgans from the sex locus, whereas the locus conferring resistance was 2.0 centimorgans from plum-eye on chromosome II. Ace.1 coding for AChE1, which is associated with resistance, is therefore autosomal. We propose that Ace.x is the recently postulated Ace.2 coding for the biochemically distinct AChE2, which is not associated with resistance.
\end{abstract}

Keywords: acetylcholinesterase, sex-linked gene, Culex pipiens, insecticide resistance.

\footnotetext{
* The results of this paper were determined separately by two laboratories $(1+2)$ and combined into a single paper for clarity.

$\uparrow$ Present address: Department of Zoology, University of British Columbia, 6270 University Boulevard, Vancouver B.C., Canada V6T 1 Z4.

tPresent address: Department of Molecular Genetics, Heart Science Centre, Harefield Hospital, Hill End Road, Harefield, Middlesex UB9 6JH, UK.

Received 6 January 1997; accepted 27 August 1997. Correspondence: Dr C. A. Malcolm, School of Biological Sciences, Queen Mary and Westfield College, University of London, Mile End Road, London E1 4NS, UK. e-mail: c.a.malcolm@qmw.ac.uk.
}

\section{Introduction}

AChE (EC 3.1.1.7) catalyses the hydrolysis of the neurotransmitter acetylcholine (ACh) and thus is a key enzyme at cholinergic synapses in the insect central nervous system (see Toutant, 1989). Its inhibition by organophosphates and carbamates causes a desensitization of the ACh receptor leading to a blockage of nerve impulse transmission (Eldefrawi, 1976; Eldefrawi et al., 1982).

Culex pipiens is a complex of species and/or geographical, or physiological forms, with a worldwide distribution (Harbach et al., 1985; Miller et al., 1996). In tropical and subtropical regions they are major vectors of filariasis and arboviruses and in many temperate regions a serious biting nuisance. $C$. pipiens has been subject to extensive control measures using insecticides and has evolved multiple resistance mechanisms. Important are two conferring resistance to organophosphates: one involves overproduction of esterases conferring an increased ability to detoxify the insecticide, the other is mediated by an acetylcholinesterase (AChE) insensitive to insecticide inhibition (Bourguet et al., 1996a; Raymond \& Pasteur, 1996). Propoxur-insensitive AChE in $C$. pipiens was first reported in a strain (MSE) selected from a resistant population collected in Southern France (Raymond et al., 1985). Genetic analysis of this strain attributed most of the insecticide resistance to a single gene, which from the previous studies coded for an insensitive AChE (Raymond et al., 1985, 1987).

Insensitive AChEs have been detected in more than twenty-five insect species (Fournier \& Mutéro, 1994). In order to identify the mutation(s) conferring insecticide insensitivity, genes coding AChE (Ace) have been cloned and sequenced in some insect species including: Drosophila melanogaster (Hall \& Spierer, 1986), Anopheles stephensi (Hall \& Malcolm, 1991), Aedes aegypti (Anthony et al., 1995), Leptinotarsa decemlineata (Zhu \& Clark, 1995) and Musca domestica (Williamson \& Devonshire, pers. comm.).

Although vertebrates have two cholinesterases, $\mathrm{AChE}$ and butyrylcholinesterase (BuChE, EC 3.1.1.8), 


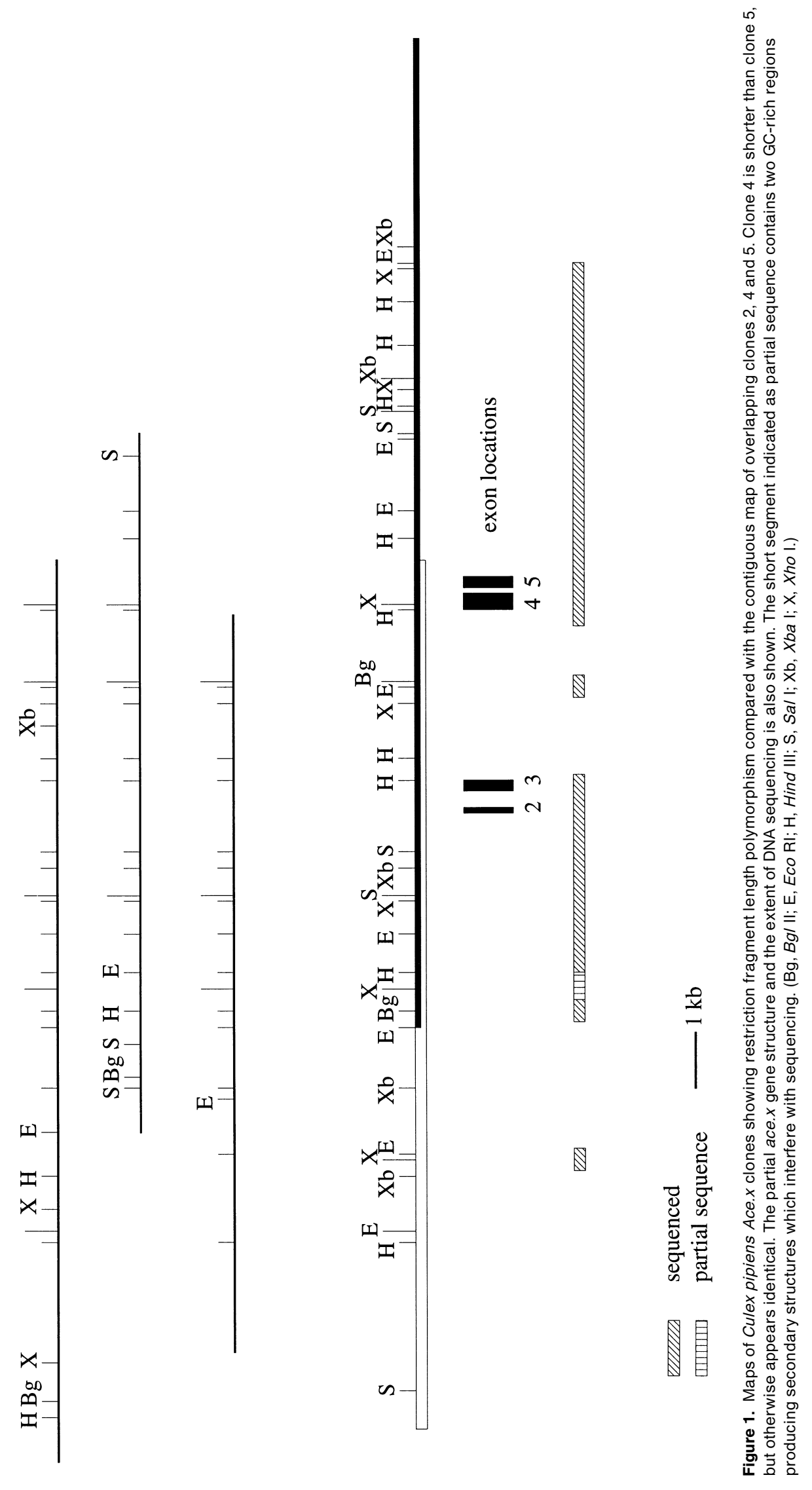


only one was reported in arthropods (Toutant, 1989). However, two AChEs, AChE1 and AChE2, have recently been described in C. pipiens (Bourguet et al., 1996a). These enzymes differ in their substrate specificity, inhibitor sensitivity and electrophoretic migration pattern, but display identical sedimentation profiles. Two cholinesterases, with different properties, are also present in gnathostome vertebrates and in amphioxus and are the product of distinct genes (Massoulié et al., 1993; Sutherland et al., 1997). In vertebrates an alternative splicing of the mRNA produced by one of the two cholinesterase genes gives two peptides, but they have identical catalytic properties. It is unlikely that Culex pipiens AChE1 and AChE2 proteins derive from post-translational modifications or an alternative splicing of the mRNA of a single gene, so that AChE1 and AChE2 are thought to be the product of two distinct genes: Ace. 1 and Ace.2 (Bourguet et al., 1996a).

This paper presents the initial characterization of an acetylcholinesterase gene, provisionally named Ace.x in Culex pipiens, and the analysis of its inheritance in relation to insecticide resistance due to insensitive AChE1. DNA sequence from intact open reading frames corresponding to exons 2-5 was obtained, showing $93 \%$ identity of deduced amino acid sequence to Anopheles stephensi Ace. Ace.x was found to be tightly linked to the sex locus (linkage group I), whereas Ace. 1 is located on linkage group III. We suggest that Ace.x is the putative second gene Ace.2 proposed by Bourguet et al. (1996a).

\section{Results}

\section{Sequence analysis of Ace.x}

A homologous $A C h E$ gene probe $(F G)$ was used to screen an unamplified MSE genomic DNA library from which six clones were isolated and fully characterized. A $2.2 \mathrm{~kb}$ Hind III-Xho I fragment (Fig. 1), containing regions of homology to the $F G$ probe, was subcloned from clone 5 . This was sequenced and found to contain intact open reading frames, which by comparison to the An. stephensi AChE gene, corresponded to exons 2 and 3 (Fig. 2a). The sequence analysis was repeated and extended with clone 2 by shot-gun subcloning of fragments generated with Hind III, Xho I, Eco RI and Sal I into M13, pUC18 and pUC19. The sequence obtained encompassed open reading frames corresponding to exons 2-5 (Fig. 2b). The overlapping sequence with clone 5 was identical. Despite extensive sequencing of the regions flanking exons 2 and 5 (Fig. 1), no further exons were identified, presumably indicating that introns 1 and 5 are very large.
A comparison of the predicted amino acid sequence for exons 2-5 with other Dipteran AChEs is shown in Fig. 3. A high degree of AChE sequence identity ( $\sim 93 \%$ ) can be observed between the mosquitoes. This is reflected in the results of a phylogenetic tree based on the available AChE sequence data (including unpublished data for An. albimanus, and $A n$. gambiae), which shows that the mosquitoes form a monophyletic group within the Diptera (Fig. 4). An. stephensi and An. gambiae, which both belong to the subgenus Cellia (Gillies \& De Meillon, 1968; Rao, 1984), are distinct from An. albimanus, which belongs to the subgenus Nyssorhynchus (Pan American Health Organisation, 1996). C. pipiens and Ae. aegypti are separate from the Anopheles although the bootstrap value suggests less confidence in this distinction.

Given the possibility of two Ace genes in C. pipiens (Bourguet et al., 1996a), and the observation of restriction fragment length polymorphism (RFLP) in the isolated clones (Fig. 1) from a strain homozygous for insecticide-insensitive AChE, it was necessary to investigate the relationship between the clones. All six clones were used to provide templates for PCR amplification of fragments encompassing part of exon 2 through to part of exon 3. The fragments were subsequently analysed by direct sequencing and restriction digests. Clone 3 was single and double digested with Hind III and Xho I, and shot-gun subcloned into pUC19 and pUC18 and the subclones partially sequenced. All of the sequences obtained from the regions in which the restriction maps were fully conserved were identical to corresponding sequence already obtained from clones 2 and 5 . Cross-hybridization between fragments of different clones showed cross homology even within the less conserved $5^{\prime}$ regions. The clones therefore appear to contain alleles of the Ace.x locus. The sequence analysis was not extensive enough to establish if there were any differences at all in the coding regions between the clones.

\section{Inheritance of Ace.x}

RFLP on genomic DNA. EcoRI digestion of genomic DNA revealed 3 fragments $(4.7,3.4$ and $2.9 \mathrm{~kb})$ hybridizing with the Ace.x probe (Fig. 6). These were named respectively as $A, B$ and $C$. Females of the susceptible strain S-lab (S) had only $C$, and those from the resistant strain MSE (M) had only $A$. MSE males had $A$ and $B$ fragments. The inheritance of these fragments was studied by analysing the male and female offspring of the cross $S \times M$ and backcrosses $S \times(S \times M)$, $(\mathrm{S} \times \mathrm{M}) \times \mathrm{M}$ and $\mathrm{M} \times(\mathrm{S} \times \mathrm{M})($ Fig. 5$)$.

The results (Table 1 ) were in agreement with a mendelian segregation of three alleles at the same 
$\begin{array}{ccccccr}10 & 20 & 30 & 40 & 50 & 60 & 70 \\ 1 & 1 & 1 & 1 & \mid & \mid & \mid \\ \text { CTATATCAATTTTATTTCATCTTTTCCGTGTGTGTGTTTTTTCTTTCTTCAGATATGAATATTTCCCG }\end{array}$

$\begin{array}{lllllllllllllllllllllll}\mathbf{Y} & I & \mathbf{N} & \mathbf{F} & \mathbf{Y} & \mathbf{F} & \mathbf{I} & \mathbf{F} & \mathbf{S} & \mathbf{V} & \mathbf{C} & \mathbf{V} & \mathbf{F} & \mathbf{F} & \mathbf{S} & \mathbf{F} & \mathbf{F} & \mathbf{R} & \mathbf{Y} & \mathbf{E} & \mathbf{Y} & \mathbf{F} & \mathbf{P}\end{array}$ $\begin{array}{lllllll}80 & 90 & 100 & 110 & 120 & 130 & 140\end{array}$ $\begin{array}{llllll}8 & 1 & 1 & 1 & 1\end{array}$

GGTTTTGCCGGCGAGGAAATGTGGAATCCCAACACAAACGTATCGGAGGACTGTCTGTATCTGAACATTT

$\begin{array}{llllllllllllllllllllllll}G & \mathbf{F} & \mathbf{A} & \mathbf{G} & \mathbf{E} & \mathbf{E} & \mathbf{M} & \mathbf{W} & \mathbf{N} & \mathbf{P} & \mathbf{N} & \mathbf{T} & \mathbf{N} & \mathbf{V} & \mathbf{S} & \mathbf{E} & \mathbf{D} & \mathbf{C} & \mathbf{L} & \mathbf{Y} & \mathbf{L} & \mathbf{N} & \mathbf{I}\end{array}$ $\begin{array}{lllllll}150 & 160 & 170 & 180 & 190 & 200 & 210\end{array}$ GGGTACCAACGAAAACCCGTTTGCGCCACGGACGAGGACTAAACTTTGGAAACAACGACGTATGTACTTC $\begin{array}{llllllllllllllllllll}\mathbf{W} & \mathbf{V} & \mathbf{P} & \mathbf{T} & \mathbf{K} & \mathbf{T} & \mathbf{R} & \mathbf{L} & \mathbf{R} & \mathbf{H} & \mathbf{G} & \mathbf{R} & \mathbf{G} & \mathbf{L} & \mathbf{N} & \mathbf{F} & \mathbf{G} & \mathbf{N} & \mathbf{N} & \mathbf{D}\end{array}$

$\begin{array}{lllllll}220 & 230 & 240 & 250 & 260 & 270 & 280\end{array}$
TTCTTCTTGTTAGTACACAGTACGACAGAAAAATGTCGATGATGGCTCTGTCAGAAGTTTTTTGACAATC

$\begin{array}{lllllll}290 & 300 & 310 & 320 & 330 & 340 & 350\end{array}$

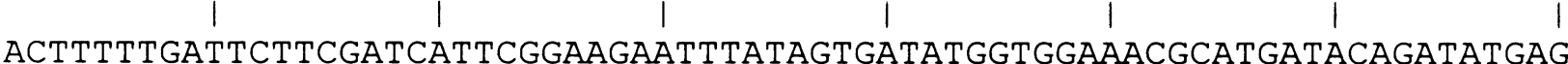
$\begin{array}{ccccccc}360 & 370 & 380 & 390 & 400 & 410 & 420 \\ 1 & 1 & 1 & 1 & \mid & \mid & \mid \\ \text { AACTAACTAACTTGACATTTCTGTCGAGCTGTGCTGTGATGATTTAGTTGTTCGTGGCTCTGAGAGAGAC }\end{array}$ $\begin{array}{ccccccc}430 & 440 & 450 & 460 & 470 & 480 & 490 \\ 1 & 1 & 1 & 1 & 1 & 1 & 1\end{array}$ AGgTCCAGAGTGTATTTTTAGTAGTTGCGTAGGCGTTTATGCACCCACAACGGAGATAATTCACAAGGTT
500
510
520
530
540
550
560

TTTTTTCTTTCTTTTTGTTTTTCCCCTCTGGCATGCCGTGGCCACCTCTTTATTGCAGTACTTCCAGG

$$
570
$$

580

590

600

610

620

Y $\mathbf{F} \mathbf{Q}$

630

ACGATGATGACTTCCAGCGGCAGCACCAGTCCAAGGGCGGCCTCGCGATGCTGGTCTGGATCTACGGGGG

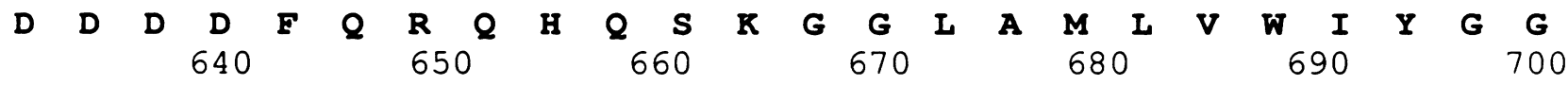
TGGGTTTATGAGCGGAACATCAACGTTGGACGTTTACAACGCAGAAATACTGGCGGCCGTTGGGAACGTA
G $\quad \mathbf{F}$
S $\mathbf{G}_{720} \mathbf{T}$
T 130
$\begin{array}{llc}\mathbf{P} & \mathbf{Y} \\ 740\end{array}$
A $\mathbf{E}$ I $\mathbf{L}$
$\begin{array}{llllll}A & A & \mathbf{V} & \mathbf{G} & \mathbf{N} & \mathbf{V}\end{array}$ 1

ATCGTGGCCTCGATGCAGTACCGAGTGGGAGCATTCGGTTTCTTCTACCTTTCGCCCTACTTGAACGGCC
I $\quad V_{780}$
M 2
790
R $\begin{gathered}\mathbf{V} \\ 800\end{gathered}$
A ${ }_{810}^{\mathbf{F}}$
F 820
S $\mathbf{P}$
830
L $\mathbf{N} \mathbf{G}$ GTGAAGAGGAGGCTCCAGGTGGGATAATGATGGCGATGTTTTGATGCTTTACGCGCGCGCGATTTAATTT $\begin{array}{lllllll}\mathbf{R} & \mathbf{E} & \mathbf{E} & \mathbf{E} & \mathbf{A} & \mathbf{P} & \mathbf{G}\end{array}$

Figure 2(a). DNA sequence and inferred amino acid sequence of Culex pipiens AChE gene: exons 2 and 3 . 


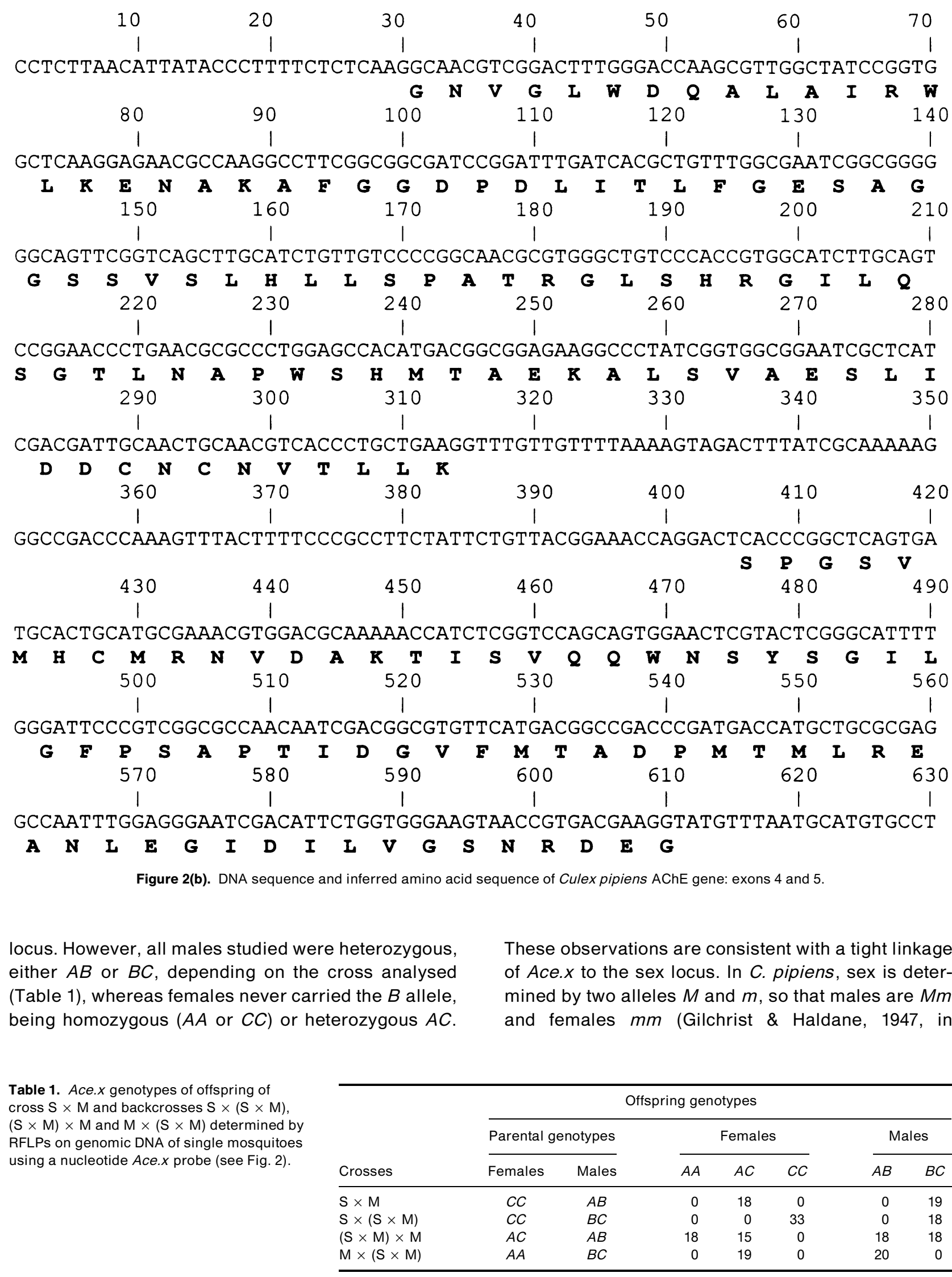


C. pipiens

A. stephensi

Ae. aegypti

D. melanogaster

L. decemlineata

C. pipiens

A. stephensi

Ae. aegypti

D. melanogaster

L. decemlineata

C. pipiens

A. stephensi

Ae. aegypti

D. melanogaster

L. decemlineata

C. pipiens

A. stephensi

Ae. aegypti

D. melanogaster

L. decemlineata

c. pipiens

A. stephensi

Ae. aegypti

D. melanogaster

L. decemlineata
110

20

30

40

50

YEYFPGFAGEEMWNPNTNVSEDCLYLNIWVPTKTRLRHGRGLNFGNNDYFQ . DDDDFQR

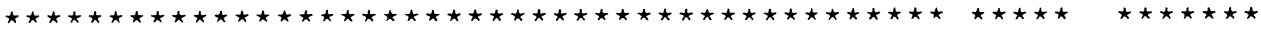
YEYFPGFAGEEMWNPNTNVSEDCLYLNIWVPTKTRLRHGRGLNFGSNDYFQ . . DDDDFQR

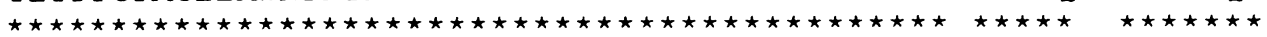
YEYFPGFAGEEMWNPNTNVSEDCLYLNIWVPTKTRLRHGRGLNFGNNDYFQ . . DDDDFQR

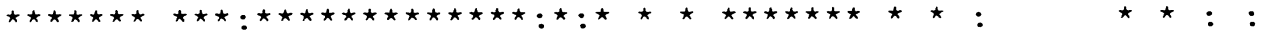
YEYFPGESGEE IWNPNTNVSEDCLY INVWAPAKARLRHGRGANGGEHPNGKQADTDHLIH

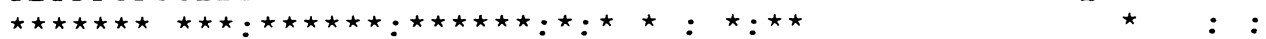
YEYEPGFEGEEMWNPNTNISEDCLYLNIWVPQRLRIRHHA. . . . . . . DKPTIDR $\begin{array}{lllll}1 & 10 & 20 & 30 & 40\end{array}$
60
70
80
90
100
110

Q. . HQSKGGLAMLVWIYGGGFMSGTSTLDVYNAE I LAAVGNV IVASMQYRVGAFGFFYL

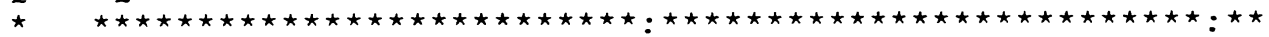
Q. .. HQSKGGLAMLVWIYGGGFMSGTSTLDIYNAE I IAAAVGNVIVASMQYRVGAFGFLYL

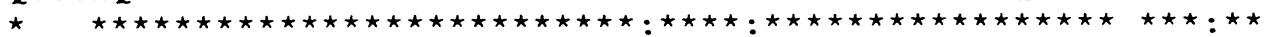
Q. . HQSKGGLAMLVWIYGGGFMSGTSTLDVYNAEMLAAVGNVIVASMQYRVGSFGFFYL

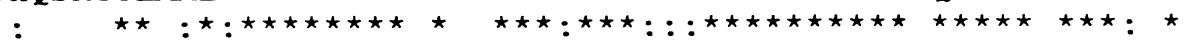
NGNPQNTTNGLPI LIWIYGGGFMTGSATLDI YNADIMAAVGNVIVASFQYRVGAFGFLHL

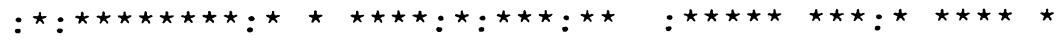
P....... KVPVLIWIYGGGYMSGTATLDVYDADI IAATSDVIVASMQYRLGSFGFLYL $\begin{array}{lllrr}50 & 60 & 70 & 80 & 90\end{array}$
120
130
140
150
160
170

SPYL. NGREEEAPGNVGLWDQALAIRWLKENAKAFGGDPDLITLFGESAGGSSVSLHLLS

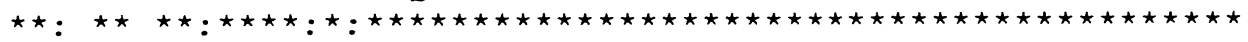
APYI . NGYEEDAPGNMGMWDQALAIRWLKENAKAFGGDPDLITLFGESAGGSSVSLHLLS

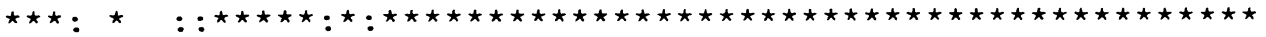
APYL. N. . DDDAPGNVGLWDQALAIRWLKENAKAFGGDPDLITLFGESAGGSSVSLHLLS

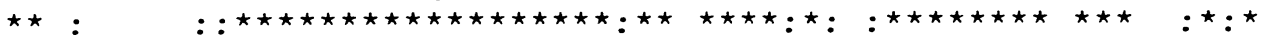
APEMPSEFAEEAPGNVGLWDQALAIRWLKDNAHAFGGNPEWMTLFGESAGSSSVNAQLMS

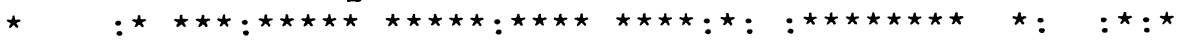
NRY FPRG. SDETPGNMGLWDQI LAIRWIKDNAAAFGGDPDLITLFGESAGGGSISIHLIS $\begin{array}{lllll}110 & 120 & 130 & 140 & 150\end{array}$
180
190
200
210
220
230

PATRGLSHRGILQSGTLNAPWSHMTAEKALSVAES L IDDCNCNVTLLKDS PGSVMHCMRN

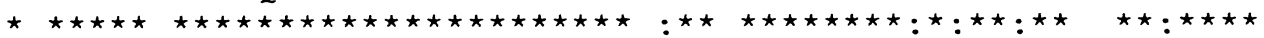
PVTRGLSKRGILQSGTLNAPWSHMTAEKALQIAEGLIDDCNCNLTMLKESPSTVMQCMRN

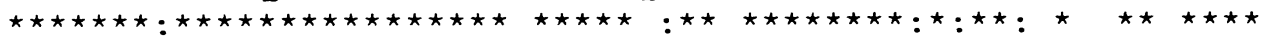
PVTRGLSRRGI LQSGTLNAPWSHMSAEKALSVAEALIDDCNCNVTLLKDNPNYVMNCMRN

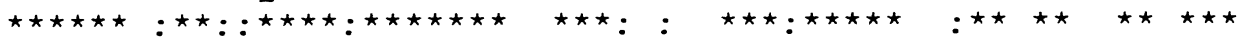
PVTRGLVKRGMMQSGTMNAPWSHMTSEKAVE I GKALINDCNCNASMLKTNPAHVMSCMRS

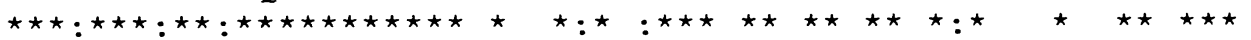
PVTKGLVRRGIMQSGTMNAPWSYMSGERAEQI GKILIQDCGCNVS LLENSPRKVMDCMRA $\begin{array}{llll}170 & 180 & 190 & 200\end{array}$
240
250
260
270
280
290

VDAKT ISVQQWNSYSGI LGFPSAPT IDGVFMTADPMTMLREANLEGIDI LVGSNRDEG

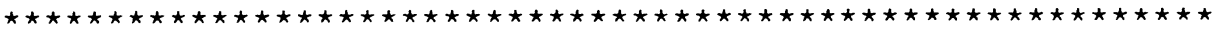
VDAKTISVQQWNSYSGI LGEPSAPT IDGVEMTADPMTMLREANLEGIDI LVGSNRDEG

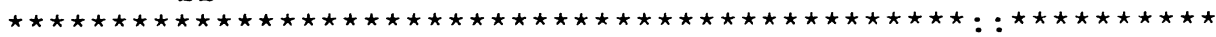
VDAKT ISVQQWNSYSGI LGEPSAPT IDGVFMTADPMTMLREANLEGVE I LVGSNRDEG

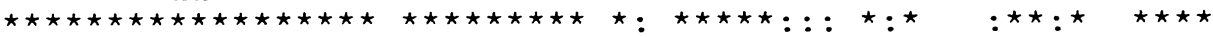
VDAKT ISVQQWNSYSGI LSFPSAPT IDGAFLPADPMTLMKTADLKDYDI LMGNVRDEG

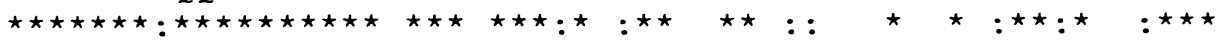
VDAKT IS LQQWNSYSGI LGFPSTPT IEGV LLPKH PMDMLAEGDYEDME I LLGSNHDEG
230
240
250
260
270
276 


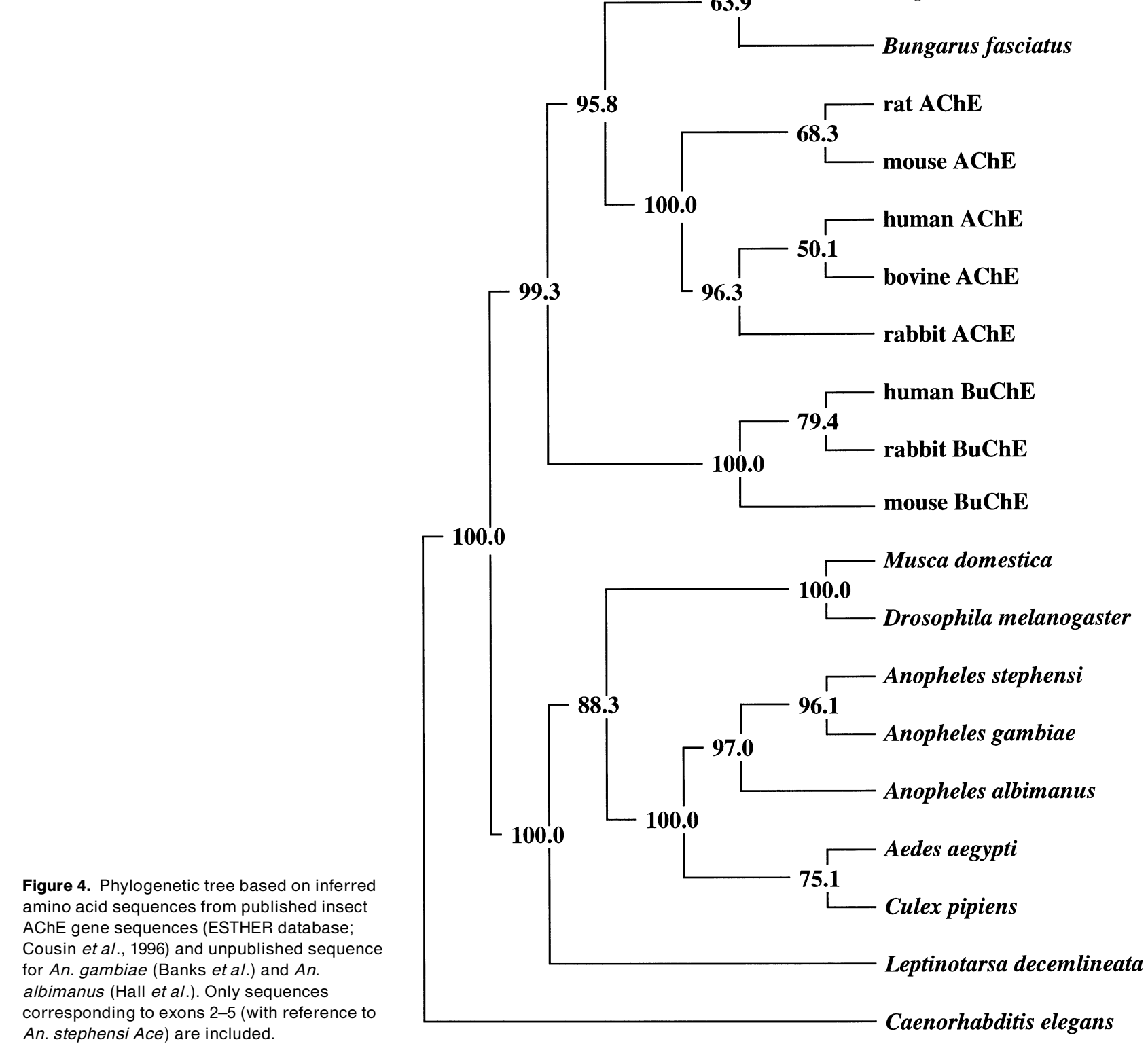

Clements, 1992). Thus, the offspring of the $S \times M$ cross between $m C / m C$ females and $m A / M B$ males gave $m C / m A$ females and $m C / M B$ males. The backcross $(\mathrm{S} \times \mathrm{M}) \times \mathrm{M}$ between $m C / m A$ females and $m A / M B$ males gave $m A / m A$ and $m A / m C$ females, plus $m A / M B$ and $m c / M B$ males. The backcross of $S \times(S \times M)$ between $m C / m C$ females and $m C / M B$ males gave $m C / m C$ females and $m C / M B$ males. Finally, the backcross $\mathrm{M} \times(\mathrm{S} \times \mathrm{M})$ between $m A / m A$ females and $m C / M B$ males gave $m C / m A$ females and $m A / M B$ males. No recombinants between Ace. $x$ and the sex locus were detected $(n=196)$, indicating that the two loci are at less than 1.5 units of recombination at the 0.05 confidence level.

Figure 3. Alignment of inferred amino acid sequences from published insect AChE gene sequences. Only sequences corresponding to exons $2-5$ (with reference to An. stephensi Ace) are included (Anthony et al., 1995; Hall \& Malcolm, 1991; Hall \& Spierer, 1986; Malcolm \& Hall, 1990; Zhu et al., 1996). 

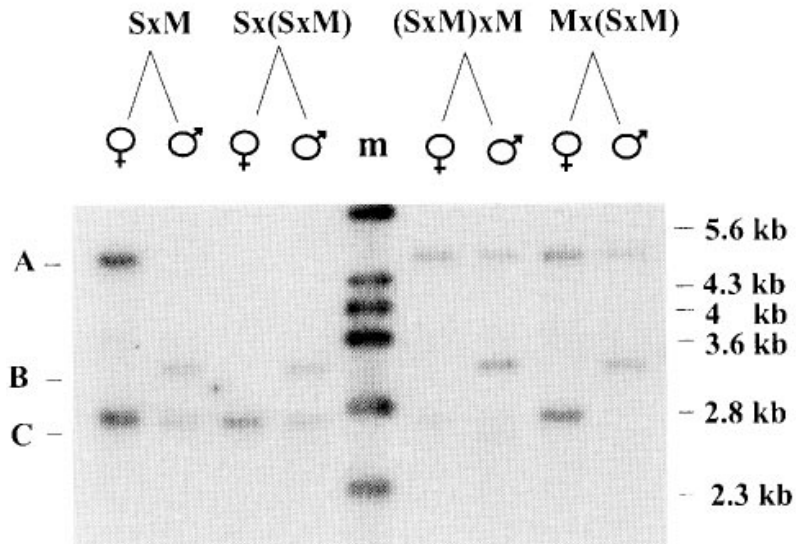

Figure 5. RFLP profiles of males and females of cross $S \times M$ and backcrosses $S \times(S \times M),(S \times M) \times M$ and $M \times(S \times M)$ obtained on genomic DNAs using a 700 bp Ace. $x$ probe. $\mathrm{m}=$ marker.

RFLP on PCR products. The 700 bp fragments of Ace.x amplified from MSE and S-lab DNAs, then digested with Sca I, are shown in Figs 5 and 6. Both strains produced $230 \mathrm{bp}$ fragments, but in S-lab the remaining $470 \mathrm{bp}$ fragment was cut into $350 \mathrm{bp}$ and
$120 \mathrm{bp}$. This polymorphism is described here as allele D (470 and $230 \mathrm{bp}$ ), characteristic of MSE, and allele $\mathrm{E}$ $(350,230$ and $120 \mathrm{bp})$, characteristic of S-lab.

Male and female offspring of cross $\mathrm{S} \times \mathrm{M}$ and three backcrosses were analysed to determine their genotypes (Figs 6 and 7 and Table 2). As expected, all offspring from $\mathrm{S} \times \mathrm{M}$ displayed four bands (i.e. 470, 350,230 and $120 \mathrm{bp}$ ) corresponding to the heterozygous $D E$ genotype. If Ace.x is autosomally inherited, the backcrosses are expected to produce $50 \%$ homozygotes ( $D D$ or $E E$ depending on the backcross considered) and $50 \%$ heterozygotes $D E$ in both sexes. This was the case for backcross $(S \times M) \times M$ with heterozygous female parents, but not for the other two where the male parent was heterozygous, thus confirming that Ace.x is close to the sex locus. No recombinants between Ace.x and the sex locus were detected $(n=165)$, giving a genetic distance between the two loci below 1.8 units of recombination at the 0.05 confidence level.

Both methods therefore indicate that the Ace.x gene is tightly linked to the sex locus; taken together no

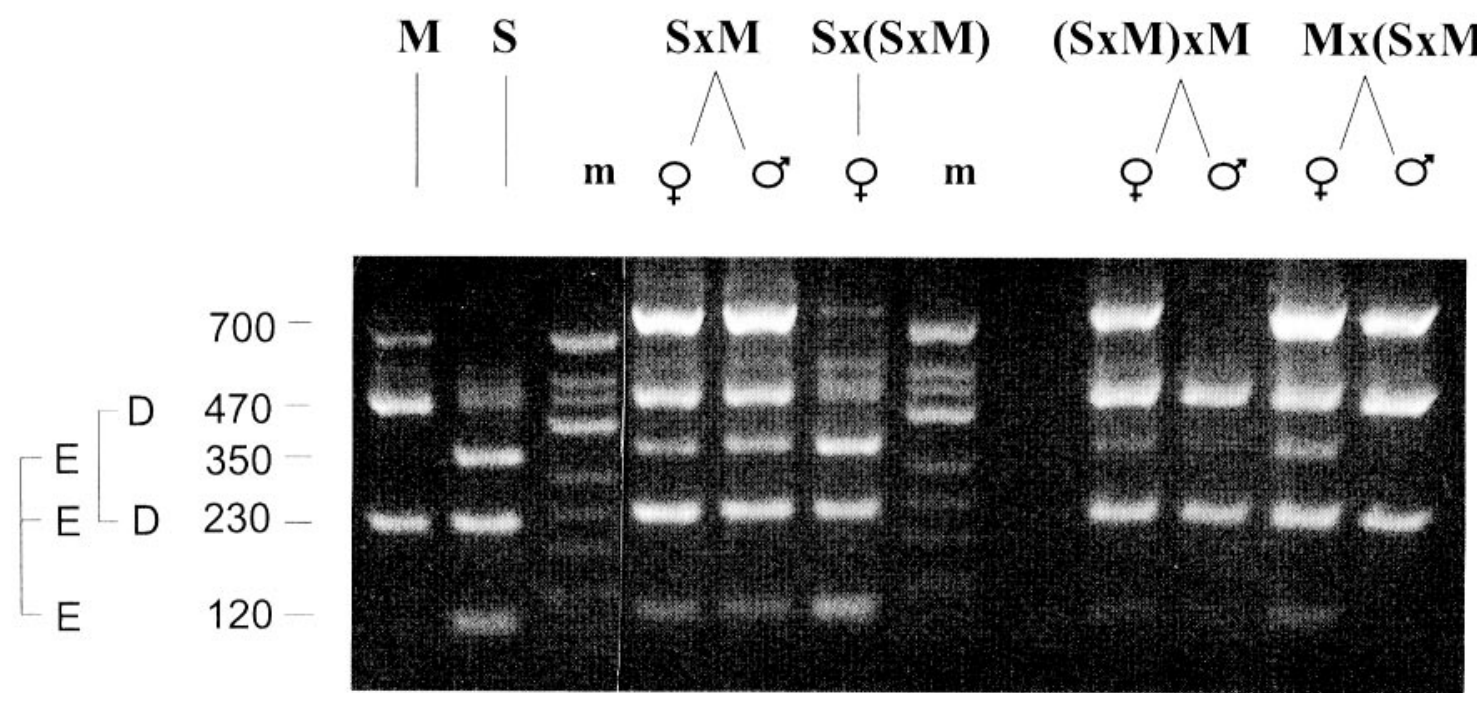

Figure 6. RFLP profiles of males and females of cross $S \times M$ and backcrosses $S \times(S \times M),(S \times M) \times M$ and $M \times(S \times M)$ obtained on a 700 bp PCR product of Ace.x probe. $\mathrm{m}=$ marker.

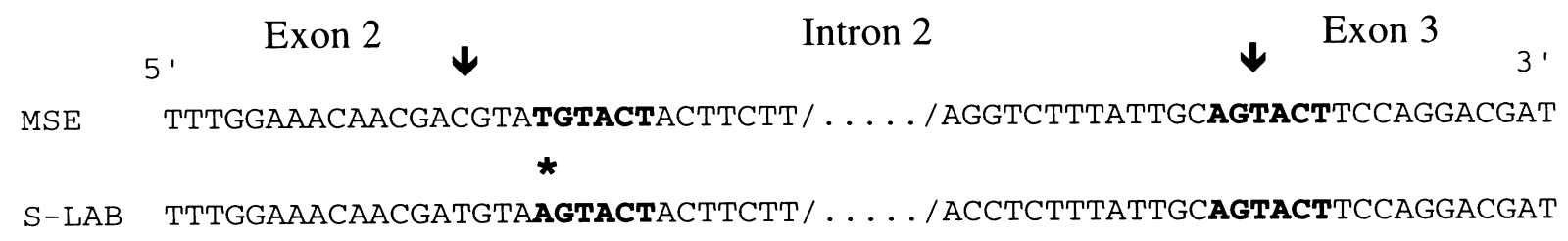

ScaI

ScaI

Figure 7. Scal restriction sites on the $700 \mathrm{bp}$ fragment. Mosquitoes from the S-LAB strain possesses two restriction sites whereas only one is present on individuals from the MSE strain. This difference was due to a single pair base mutation (*). Thus, the Sca I restriction site (located at the beginning of the intron 2), allows the discrimination between alleles of each strain. Arrows indicate the intron/exon junctions. 
Table 2. Ace. $x$ genotypes of offspring of cross $\mathrm{S} \times \mathrm{M}$ and backcrosses $\mathrm{S} \times(\mathrm{S} \times \mathrm{M})$, $(\mathrm{S} \times \mathrm{M}) \times \mathrm{M}$ and $\mathrm{M} \times(\mathrm{S} \times \mathrm{M})$ determined by RFLPs on a 700 bp PCR product of Ace.x (see Fig. 3).

\begin{tabular}{|c|c|c|c|c|c|c|c|c|}
\hline \multirow[b]{3}{*}{ Crosses } & \multicolumn{8}{|c|}{ Offspring genotypes } \\
\hline & \multicolumn{2}{|c|}{ Parental genotypes } & \multicolumn{3}{|c|}{ Females } & \multicolumn{3}{|c|}{ Males } \\
\hline & Females & Males & $E E$ & $E D$ & $D D$ & $E E$ & $E D$ & $D D$ \\
\hline $\mathrm{S} \times \mathrm{M}$ & $E E$ & $D D$ & 0 & 15 & 0 & 0 & 15 & 0 \\
\hline $\mathrm{S} \times(\mathrm{S} \times \mathrm{M})$ & $E E$ & $E D$ & 40 & 0 & 0 & 0 & 39 & 0 \\
\hline$(S \times M) \times M$ & $E D$ & $E E$ & 0 & 10 & 9 & 0 & 13 & 15 \\
\hline$M \times(S \times M)$ & $D D$ & $E D$ & 0 & 42 & 0 & 0 & 0 & 44 \\
\hline
\end{tabular}

\begin{tabular}{|c|c|c|c|c|c|c|c|c|}
\hline \multirow[b]{3}{*}{ Crosses } & \multicolumn{8}{|c|}{ Offspring genotypes } \\
\hline & \multicolumn{2}{|c|}{ Parental genotypes } & \multicolumn{3}{|c|}{ Females } & \multicolumn{3}{|c|}{ Males } \\
\hline & Females & Males & sS & $R S$ & $R R$ & SS & $R S$ & $R R$ \\
\hline$S \times M$ & SS & $R R$ & 0 & 96 & 0 & 0 & 96 & 0 \\
\hline$S \times(S \times M)$ & SS & $R S$ & 31 & 33 & 0 & 32 & 32 & 0 \\
\hline $\mathrm{M} \times(\mathrm{S} \times \mathrm{M})$ & $R R$ & $R S$ & 0 & 29 & 35 & 0 & 31 & 33 \\
\hline
\end{tabular}

Table 3. Ace. 1 genotypes of offspring of cross $\mathrm{S} \times \mathrm{M}$ and backcrosses $\mathrm{S} \times(\mathrm{S} \times \mathrm{M})$ and $\mathrm{M} \times(\mathrm{S} \times \mathrm{M})$ determined by characterizing the inhibition characteristics of AChE enzyme in single mosquitoes. $R$ and $S$ alleles correspond to $A c e .1^{R}$ and $A c e .1^{S}$ respectively. recombinants were detected from 361 individuals giving a genetic distance below 0.8 centimorgans at the 0.05 confidence level.

\section{Inheritance of the Ace.1 gene}

Ace. 1 inheritance was investigated by analysing the inhibition properties of the AChE1 enzyme in the offspring of various crosses (Table 3 ). As expected, all mosquitoes from the $S$ strain were Ace. $1^{\text {SS }}$ and all those from the $\mathrm{M}$ strain Ace. $1^{R R}$. All mosquitoes of the $\mathrm{F} 1(\mathrm{~S} \times \mathrm{M})$ offspring were Ace. $1^{R S}$ heterozygous, and segregation of the Ace. 1 alleles in offspring of backcrosses $\mathrm{S} \times(\mathrm{S} \times \mathrm{M})$ and $\mathrm{M} \times(\mathrm{S} \times \mathrm{M})$ was consistent with an autosomal localization of Ace.1. In particular, there were no difference in the proportions of males and females carrying the same genotype $(P>0.8)$, as well as in the expected proportion of Ace. $1^{R S}$ genotypes (Table 3).

To further confirm that insecticide resistance conferred by Ace. $1^{R}$ is not sex-linked, the sex ratio in offspring of backcross $S \times(S \times M)$ was studied among mosquitoes which had survived different insecticide exposures (Table 4). The insecticide doses used completely inhibit sensitive AChE1, so that no Ace. $1^{\text {SS }}$ individuals survive, Ace. $1^{R S}$ mosquitoes are partly resistant and $A c e .1^{R R}$ individuals are unaffected. If males and females from backcross $S \times(S \times M)$ have different Ace. 1 genotypes, a sex-ratio bias is expected after insecticide treatments. Compared with the control, no sex ratio bias was observed in mosquitoes which had survived exposure to propoxur doses inducing a mortality of $29 \%$ and $95 \%$ or to a chlorpyrifos dose inducing 74\% mortality (Table 4).
Finally, the linkage relationships of Ace. 1 with plum eye was investigated. This gene is a marker of one of the two autosomes localized in linkage group III of C. pipiens. The strain YPL, which is homozygous for the sensitive AChE1 allele and plum eye, was used in crosses with MSE, which is homozygous for insensitive AChE1 and wild-type eye. The eye phenotype of offspring from the backcross $\mathrm{Y} \times(\mathrm{Y} \times \mathrm{M})$, reared in absence of insecticide (control), or exposed during $24 \mathrm{~h}$ to $0.025 \mathrm{ppm}$ of chlorpyrifos, were compared. In the control, the proportion of eye phenotypes was not different from 1:1 $(P>0.5)$. Chlorpyrifos gave a mortality rate of $65 \pm 3 \%$. As this insecticide concentration kills all susceptible Ace. $1^{\text {ss }}$ mosquitoes, survivors were only heterozygous $\left(\right.$ Ace. $\left.1^{R S}\right)$. Among them, 254 had wild-type eyes, indicating a $p / A c e .1^{S} /+A c e .1^{R}$

Table 4. Larval mortality and sex ratio of offspring of $S \times(S \times M)$ cross in the presence of various concentrations of two insecticides: propoxur (a carbamate) and chlorpyrifos (an organophosphate). For each concentration, larval mortality was estimated after $24 \mathrm{~h}$ of insecticide exposure and sex-ratio were calculated on adults. Differences between the number of surviving larvae and of adults are due to delayed mortality. Fisher's exact tests were performed to evaluate sex ratio biases.

\begin{tabular}{lcccc}
\hline & Dose $^{\mathrm{a}}$ & $\%$ Mortality $(n)^{\mathrm{b}}$ & Sex ratio $^{\mathrm{c}}(n)^{\mathrm{d}}$ & $P$ \\
\hline Propoxur & 0 & $0(280)$ & $1.17(276)$ & - \\
& 2 & $29(320)$ & $1.21(203)$ & 0.93 \\
Chlorpyrifos & 0 & $95(1200)$ & $1.39(55)$ & 0.65 \\
& 0.02 & $0(120)$ & $0.88(119)$ & - \\
& 0 & $74(360)$ & $0.79(68)$ & 0.76 \\
\hline
\end{tabular}

${ }^{\mathrm{a}}$ Insecticide concentration in $\mathrm{mg} / \mathrm{l} .{ }^{\mathrm{b}}$ Number of larvae tested.

${ }^{c}$ Ratio males/females. ${ }^{d}$ Number of adult emerged. 
Table 5. Linkage relationship between chlorpyrifos resistance $\left(\right.$ Ace. $\left.1^{R}\right)$ and eye phenotype controlled by the plum-eye locus, observed in the offsprings of backcross $Y \times(Y \times M)$.

\begin{tabular}{lcrc}
\hline & \multicolumn{2}{c}{ Phenotypes } & \\
\cline { 2 - 3 } & Wild-type & Plum & Total \\
\hline Control & 103 & 106 & 209 \\
Selected $^{\mathrm{a}}$ & 254 & 5 & 259 \\
\hline
\end{tabular}

${ }^{\mathrm{a}} 0.025 \mathrm{ppm}$ chlorpyrifos.

genotype, and five displayed a plum-eye phenotype indicating a plAce. $1^{R} / p /$ Ace. $1^{S}$ genotype (Table 5). The gene coding chlorpyrifos resistance (i.e. Ace.1) is therefore significantly $(P<0.0001)$ associated with the plum-eye locus located on the third linkage group. The proportion of recombinant survivors gives an estimate of the genetic distance between the plumeye and Ace. 1 loci of 2 centimorgans.

\section{Discussion}

Since other mosquito AChE genes (Malcolm \& Hall, 1990; Hall \& Malcolm, 1991; Malcolm et al., 1992; Hall et al. and Banks et al., unpubl.) contain small intron, we decided to use genomic DNA clones for the analysis of the $C$. pipiens gene. However, except for intron 4, the gene apparently contains large introns and is thus more similar to that of $D$. melanogaster (Fournier et al., 1989). Nevertheless, this approach revealed evidence of heterozygosity at an AChE gene when homozygosity was expected; i.e. an observation that would have been overlooked by analysis of cDNA alone.

The inferred amino acid sequence from Ace. $x$ shows a high level of identity with the other dipteran AChEs (Fig. 3) confirming that the gene codes for an AChE. The partial gene organisation implied from comparison to other dipteran AChE genes gives intron exon boundaries identical to the An. stephensi AChE gene including the additional intron between exons 3 and 4 (Malcolm \& Hall, 1990; Hall \& Malcolm, 1991), which is absent in D. melanogaster (Fournier et al., 1989).

Despite the RFLP found in the six genomic clones, DNA sequence and cross-hybridization data supported the view that the clones contained alleles of the same gene. This is consistent with the strategy used for screening the genomic DNA library, which employed a homologous probe containing an intron. The polymorphism suggests that this AChE gene has not been subjected to strong selection, whereas resistance to organophosphates in this strain was selected to fixation. This can be compared with results from studies on the flanking regions of certain non-specific esterase genes conferring organophosphate resistance in this species, which show no RFLP despite a widespread geographical distribution (Raymond et al., 1991; Raymond \& Pasteur, 1996).

The results of the various crosses used in the linkage analysis show that Ace.x is tightly linked to the sex locus (at less than 0.8 centimorgans) whereas Ace. 1 is associated with plum-eye (at less than 2 centimorgans). The sex determining locus belongs to linkage group I which corresponds to the smallest pair of chromosomes I (Bhalla et al., 1974). Plum-eye locus belongs to linkage group III (Guptavanij \& Barr, 1979), which corresponds to the medium size chromosome II (Heyse et al., 1996). These results show unambiguously that Ace.x and Ace.1, the gene involved in insecticide resistance due to modification(s) of AChE1, are distinct. The absence of any difference between males and females at the Ace. 1 locus was previously observed in natural population studies (Raymond \& Marquine, 1994), and under laboratory conditions in crosses involving several resistant strains (Bourguet \& Raymond, unpublished results). Thus, since Ace.x is not Ace.1, we propose that it is Ace.2, and codes for the AChE2 protein recently identified by Bourguet et al. (1996a). Unfortunately, no variant of the AChE2 enzyme is presently known (i.e. AChE2 possess the same biochemical properties in all strains studied of $C$. pipiens, unpublished data) so that it is not possible to provide conclusive evidence that this protein is coded by a sex-linked gene.

The occurrence of two cholinesterases is now documented in several species. In vertebrates the situation is as follows. Gnathostome species possess two related cholinesterases, acetylcholinesterase and butyrylcholinesterase, differing by their substrate specificity (Massoulié et al., 1993). These two cholinesterases are encoded by distinct genes with approximately $50 \%$ homology at the amino acid level (Taylor, 1991). If the distinction between AChE and BuChE is usually clear in birds and mammals, these two enzymes are more similar in bony and cartilaginous fishes (e.g. Toutant et al., 1985). The situation is different in agnathan vertebrates, as only a single cholinesterase was identified in the hagfish Myxine glutinosa and the lamprey Petromyzon marinus (references in Sutherland et al., 1997). These observations have been interpreted as the possible occurrence of a gene duplication in an ancestor of the elasmobranchs accompanied by subsequent divergent evolution producing AChE and BuChE in the jawed vertebrates (Chatonnet \& Lockridge, 1989). Recently, Sutherland et al. (1997) have reported the presence of two cholinesterase activities and genes in the cephalocordate amphioxus Branchiostoma floridae and B. lanceolatum. Phylogenetic analysis suggests that these two 
genes are a result of a duplication event in the lineage of the amphioxus (Sutherland et al., 1997), although this scenario has a relative low $(76 \%)$ bootstrap support.

In invertebrates the presence of two cholinesterases has been reported in the nematode Steinernelma carpocapsae (Arpagaus et al., 1992), the medicinal leech Hirudo medicinalis (Talesa et al., 1995a), the snail Helix pomatia (Talesa et al., 1995b) and the oyster Crassostrea giga (Bocquené et al., 1997). Moreover, the nematode Caenorhabditis elegans possesses three genes encoding three different cholinesterases with specific kinetic and pharmacological properties (Arpagaus et al., 1992).

The presence of two AChEs in C. pipiens is of special interest since it was thought that insects only possess one such enzyme. This raises the question as to whether it is a general feature in mosquito genera or is restricted to $C$. pipiens. The Ace genes of $A n$. stephensi, An. albimanus, An. gambiae and $A$. aegypti (Hall \& Malcolm, 1991; Anthony et al., 1995; Hall et al., unpubl.; Banks et al., unpubl.) have strong nucleotide and deduced amino acid sequence homologies with the Ace.x gene of $C$. pipiens. The relatedness of the genes is entirely consistent with the relatedness of the species (Fig. 4) and suggests that they correspond to the same gene. If that is the case, the Ace genes presently cloned from all five mosquito species do not code for the AChE involved in the synapse junction and hence in insecticide resistance. For An. albimanus this hypothesis is supported by the absence of differences in the deduced amino-acid sequence of an Ace from a strain homozygous for insecticide insensitive AChE, compared to a cloned Ace from a susceptible strain (Hall et al., unpublished data). The presence of a valine residue at position 86 in Ace.x, which is also present in A. aegypti Ace (Anthony et al., 1995), may also be worth noting (Fig. 3). This is isoleucine in $D$. melanogaster, but a change to a valine in this species is associated with a low level of insecticide insensitivity (Fournier et al., 1992; Mutéro et al., 1994). The presence of a valine may have a role in the insecticide insensitivity of AChE2 (Bourguet et al., 1996a).

An alternative proposal is that $C$. pipiens is a special case and that Ace. 2 is the consequence of a recent duplication and transposition. Amplification of nonspecific esterase genes in organophosphate-resistant strains of $C$. pipiens is a well-established phenomenon (e.g. Pasteur \& Raymond, 1996) and recently evidence for a duplication of the Ace. 1 locus has been reported (Bourguet et al., 1996b). Furthermore, biochemical and pharmacological studies of the acetylcholinesterase activity of several mosquito species (including $A$. aegypti and $A$. stephensi) did not reveal the presence of two acetylcholinesterase enzymes (Bourguet et al., 1997).

\section{Experimental procedures}

Mosquito strains

Three strains of Culex pipiens s.l. were used: MSE (M) which is homozygous for an insecticide insensitive AChE1 (Bourguet et al., 1996c; Raymond et al., 1987); S-LAB (S) which is a standard insecticide susceptible strain (Georghiou et al., 1966) and YPL (Y) which is homozygous for the linkage group III marker plumeye and is insecticide susceptible (Guptavanij \& Barr, 1979).

\section{Cloning and DNA sequence of Ace.x}

Unless otherwise stated, all molecular biology procedures followed standard protocols described in Sambrook et al. (1989) or manufacturer's instructions. Genomic DNA from the MSE strain was extracted following the procedure described by Raymond et al. (1989). Extraction of other mosquito DNA samples followed a modified version of the procedure described by Cockburn \& Seawright (1988). The DNA was prepared from individual insects, or batches of not more than five. Insects were placed in $50 \mathrm{ml}$ of extraction buffer (1\% SDS, $50 \mathrm{~mm}$ Tris $\mathrm{HCl} \mathrm{pH} \mathrm{8.0,25} \mathrm{mM} \mathrm{NaCl,} 25 \mathrm{~mm}$ EDTA), soaked for 1-5 min and then homogenized. A further $100 \mu \mathrm{l}$ of extraction buffer was added and the tubes incubated at $68^{\circ} \mathrm{C}$ for $15 \mathrm{~min} .100 \mu \mathrm{l}$ of $3 \mathrm{~m}$ potassium acetate $(\mathrm{pH}$ 7.2) was added, the tubes were inverted several times and left on ice for $5 \mathrm{~min}$ and then centrifuged at high speed for $3 \mathrm{~min}$. The supernatant was removed and the DNA/RNA precipitated with 2 volumes of ice cold $100 \%$ ethanol. Where necessary, RNA was removed by resuspending the DNA/RNA pellet in $0.5 \mu \mathrm{g} / \mathrm{ml}$ pancreatic RNase in $10 \mathrm{~mm}$ Tris-HCl ( $\mathrm{pH} 7.5)$.

$\mathrm{PCR}$ of genomic DNA using the degenerate primers $\mathrm{F}$ and $\mathrm{G}$ were run as previously described (Malcolm et al., 1992). The primers were as follows: $F$ 5'-GA(AG)GA(AG)ATGTGGAA(TC)CC (17 mer); G 5'-ACCTA(GTA)AT(GA)CC(CTGA)CCA (14 mer). PCRs using specific primers are described below.

A genomic DNA library was prepared in the replacement bacteriophage vector $\lambda$ Dash ${ }^{\mathbb{R}}$ II and the bacterial strains P2392 and LE392 supplied by the manufacturer (Stratagene). $10 \mu \mathrm{g}$ of MSE genomic DNA was partially digested with Sau3A. Aliquots of the digest were removed after 5, 15 and $25 \mathrm{~min}$ and the digest stopped by rapid phenol/chloroform extraction and ethanol precipitation. The digested DNA was then treated with calf intestinal alkaline phosphatase. The alkaline phosphatase was inactivated and the samples were once again phenol/chloroform extracted and the DNA ethanol precipitated. The digests were checked on electrophoresis and the aliquot containing fragments within the optimum size range of $18-23 \mathrm{~kb}$ was used to set up ligations with $\mathrm{Bam} \mathrm{HI}$ Hind III digested $\lambda \mathrm{Dash}^{(\mathrm{R}}{ }^{\text {III. The }}$ library was screened unamplified by plating out batches of 25,000 recombinants using Nunc $24 \times 24 \mathrm{~cm}$ tissue culture dishes and preparing plaque lifts with Hybond- $\mathrm{N}^{\mathrm{TM}}$ (Amersham International). DNA probes were labelled with $\left[\alpha-{ }^{32} \mathrm{P}\right] \mathrm{dCTP}$ (specific activity $3000 \mathrm{Ci} / \mathrm{mmol}$, ICN Pharmaceuticals Inc.) using the Pharmacia Ready-To-Go ${ }^{T m}$ DNA labelling kit. Maxipreparations of DNA from isloated $\lambda \mathrm{Dash}^{\mathbb{R}}$ ।| clones were obtained following the protocol described by Perbal (1988). 
The Pharmacia T7 Sequencing ${ }^{\mathrm{TM}}$ Kit was used for DNA sequencing of both single- and double-stranded DNA templates. Multiple sequence alignment was performed by the program of Corpet (1988) using Dayhoff replacement values.

The phylogenetic tree was prepared using sequences obtained from the ESTHER database (Cousin et al., 1996). Heuristic searches of the most parsimonious trees were carried out on the data with both the PROTPARS program of the PHYLIP 3.57 package (Felsenstein, 1995) and PAUP version 3.1.1 (Swofford, 1993), performed with the zero-length branches collapse option. Only potentially informative sites were used for phylogenetic reconstruction, i.e. those with at least two amino acid states shared by more than one sequence. Single-site gaps were treated as a new state. To evaluate the internal support of the parsimony tree, bootstrap values were calculated from 1000 replicates of heuristic searches on the whole data set using the combination of the three programs SEQBOOT, PROTPARS and CONSENSE of the former package.

\section{Inheritance of Ace.x}

F1 crosses and backcrosses were obtained by mass-crossing adults as follows (noting the female parent first): $S \times M$ : S-LAB $\times$ MSE; $\quad S \times(S \times M): \quad S-L A B \times(S-L A B \times M S E)$ $(S \times M) \times M: \quad(S-L A B \times M S E) \times M S E ; \quad M \times(S \times M):$ $\mathrm{MSE} \times(\mathrm{S}-\mathrm{LAB} \times \mathrm{MSE}) ; \mathrm{Y} \times(\mathrm{Y} \times \mathrm{M}): \mathrm{YPL} \times(\mathrm{YPL} \times \mathrm{MSE})$.

Inheritance of Ace. $x$ was studied by RFLPs on PCR products and genomic DNAs. In both cases the two following steps were undertaken: a search of an endonuclease giving distinct restriction patterns in MSE and S-LAB mosquitoes, and an analysis of the inheritance of these patterns.

RFLP on PCR products. For both strains, genomic DNA extraction of 100 mosquitoes was performed as described by Raymond et al. (1989). A 700 bp fragment (which includes part of exon 2, intron 2, and part of exon 3) of the Ace.x gene was amplified using the oligonucleotide primers F1457 (5'-GAGGAGATGTGGAATCCCAA) and B1246 (5'-TGGAGCCTCCTCTTCACGGC). Amplifications were performed in a $50 \mu$ l volume, containing $75 \mathrm{~mm}$ Tris- $\mathrm{HCl}\left(\mathrm{pH}\right.$ 9.0), $20 \mathrm{~mm}\left(\mathrm{NH}_{4}\right)_{2} \mathrm{SO}_{4}, 0.1 \%$ $(\mathrm{w} / \mathrm{v})$ Tween 20, $1.25 \mathrm{mM} \mathrm{MgCl}_{2}, 250 \mu \mathrm{m}$ of each dNTP, $100 \mathrm{ng}$ of each primer, $10-100 \mathrm{ng}$ of adult mosquito DNA and 2.5 units of Taq polymerase (Eurogentec). The tubes were then quickly transferred to the thermal cycler (Thermocycler Crocodile II, Appligene). After $5 \mathrm{~min}$ at $93^{\circ} \mathrm{C}$, reactions were cycled thirtyfive times through the following temperature profile: $93^{\circ} \mathrm{C}$ for 1 $\min , 52^{\circ} \mathrm{C}$ for $1 \mathrm{~min}$ and $72^{\circ} \mathrm{C}$ for $90 \mathrm{~s}$. The tubes were finally incubated at $72^{\circ} \mathrm{C}$ for $10 \mathrm{~min} .100 \mu \mathrm{l} \mathrm{PCR}$ products from each strain were purified (Geneclean II Kit, Bio 101 Inc.) and resuspended in $20 \mu \mathrm{l} \mathrm{H}_{2} \mathrm{O}$. Purified PCR products were sequenced following the procedure of Rousset et al. (1992) with the primers used for amplification (i.e. F1457 and B1246). A Sca I restriction site that discriminates $M$ from $S$ mosquitoes was found in the intron part of the 700 bp fragment (Fig. 3). S mosquitoes possessed two Scal restriction sites but only one is shared with M. Thus, Scal allows an analysis of Ace.x inheritance. This was performed on single mosquito genomic DNA obtained following Qiao \& Raymond (1995). The 700 bp fragment of Ace.x of each individual was amplified as described above. Aliquots of $10 \mu \mathrm{l}$ of each amplification product were digested with Scal and loaded onto a $1.5 \%$ $(w / v)$ agarose gel with TBE buffer.

RFLP on genomic DNA. For each strain, genomic DNA extraction of 100 mosquitoes was performed according to Raymond et al. (1989). DNA was digested with several enzymes (Sal I, Sac I, Hind III, Bam HI, Eco RI, Eco RV, Pst I, Bgl II and Xba I), run on $0.8 \%(\mathrm{w} / \mathrm{v})$ agarose gels, and transferred onto a Nylon membrane according to Sambrook et al. (1989). Hybridizations were performed by random priming as described in Raymond et al. (1989). The probe used for hybridization was the $700 \mathrm{bp}$ fragment of Ace.x amplified by PCR (see above). EcoRI gave a good discrimination between MSE and S-LAB alleles, thus allowing the analysis of their inheritance which was performed using genomic DNA of single mosquitoes, extracted according to the method of Qiao \& Raymond (1995) and digested by EcoRI. Gel migration, transfer, probe labelling and hybridization were as above.

\section{Inheritance of Ace. 1}

Based on biochemical properties of AChE1 protein, two alleles have been described (Bourguet et al., 1996d): Ace. $1^{\text {s }}$ coding an insecticide sensitive AChE1 and $A c e .1^{R}$ coding a modified (i.e. insecticide resistant) AChE1. S-LAB and MSE mosquitoes are homozygous $A c e .1^{S S}$ and $A c e .1^{R R}$, respectively. Therefore inheritance of $A c e .1$ was indirectly investigated by determining the Ace. 1 genotype of single individuals from different crosses according to Bourguet et al. (1996d). Briefly, single mosquitoes homogenates in phosphate buffer were centrifuged. Supernatants were used to estimate AChE activity (according to Ellman et al., 1961) in the absence of insecticide (A0) and in the presence of $10^{-4} \mathrm{M}\left(\mathrm{A} 1\right.$ ) and $10^{-2} \mathrm{M}$ (A2) propoxur (Bayer, Leverkusen, Germany). Activities were measured on a Spectramax 250 (Molecular Devices) at $412 \mathrm{~nm}$ over a period of 15 min. Absence of A2 activity (i.e. absence of insensitive AChE1) corresponds to $A c e .1^{S S}$ genotypes. If $A 2$ is not null, then $A 0$ and A1 are compared: identical activity (i.e. indicating an absence of sensitive AChE1) corresponds to Ace. $1^{R R}$ genotypes, whereas a lower $A 1$ activity (i.e. indicating the presence of sensitive AChE1) is characteristic of Ace. $1^{R S}$ genotypes.

\section{Insecticide resistance}

Insecticide bioassays were performed in plastic cups on fourth instars as described in Raymond \& Marquine (1994). In each test, sets of twenty larvae were exposed to insecticide doses lethal for Ace. $1^{S S}$ but not for Ace. $1^{R R}$. These doses were: 2 and $10 \mathrm{mg} / /$ of propoxur and $0.2 \mathrm{mg} / /$ of chlorpyrifos (Interchim, Montluçon, France) in presence of PB (piperonyl butoxide: FLUKA AG, St Quentin, France; $5 \mathrm{mg} / \mathrm{l}$ of PB applied $4 \mathrm{~h}$ before the addition of chlorpyrifos). PB inhibits the MFO (mixed function oxidase) eventually involved in chlorpyrifos resistance (see Raymond et al., 1987). To standardize the bioassays, the final concentration of solvent (alcohol) was adjusted to $1 \%$. Controls, where larvae experienced the same conditions except the presence of the insecticide, were run at the same time. As sex determination is not easy on larvae, survivors of $24 \mathrm{~h}$ exposure were rinsed in water and reared to adults. 


\section{Ace. 1 chromosomal location}

Plum-eye phenotype $(p /)$ can be distinguished in late fourthinstars and young pupae. In homozygotes $p / / p l$, eye colour varies from light to deep purple and the ocelli of the pupae are much smaller and paler than those of wild type $+I+$. Heterozygotes $p / /+$ have wild-type eyes, as $p /$ is recessive. To analyse the association between Ace.1 and plum-eye loci, fourth-instars from the $\mathrm{Y} \times(\mathrm{Y} \times \mathrm{M})$ backcross were randomly separated into two sets: one (220 larvae) was used as control and the other (850 larvae) was exposed during $24 \mathrm{~h}$ to 0.025 ppm chlorpyrifos, a concentration killing all Ace. $1^{\text {sS }}$ so that all survivors are Ace. $1^{R S}$. All the late fourth-instars or young pupae were examined visually to determine their eye phenotype.

\section{Acknowledgements}

We are grateful to C. Bernard, M. Marquine, J. Mungroo and $G$. Pistre for technical assistance, to $G$. Benna for construction of the phylogenetic tree and to T. Guillemaud, T. Lenormand and F. Rousset for helpful comments and discussions. This work was supported in the UK by the Wellcome Trust (grant no. 034732/Z/91/ Z); A.A. was supported by grant ERBCHRXCT930172; S.J.R. and C.F.G. were supported by BBSRC CASE awards. In France the work was financed in part by an ACC-SV3 grant (no. 9503037), by EU HCM (Networks) (no. ERBCHRXCT930172), by Region Languedoc Roussillon (Arr. 963223) and by a fellowship to D.B. from MESR (no. 93082). This is contribution 97-110 of the Institut des Sciences de l'Evolution (UMR 5554). The laboratories are members of the European Network on Insect Genetics in Medicine and Agriculture (ENIGMA).

\section{References}

Anthony, N., Rocheleau, T., Mocelin, G., Lee, H.J. and ffrenchConstant, R. (1995) Cloning, sequencing and functional expression of an acetylcholinesterase gene from the yellow fever mosquito Aedes aegypti. FEBS Letters 368: 461-465.

Arpagaus, M., Richier, P., Bergé, J.-B. and Toutant, J.-P. (1992) Acetylcholinesterases of the nematode Steinernema carpocapsae: characterization of two types of amphiphilic forms differing in their mode of membrane association. Eur $J$ Biochem 207: 1101-1108.

Bhalla, S.C., Cajaiba, A.C.I., Carvalho, M.P. and Santos, J.M. (1974) Translocations, inversions and correlations of linkage groups to chromosomes in the mosquito Culex pipiens fatigans. Can $\mathrm{J}$ Genet Cytol 16: 837-850.

Bocquené, G., Roig, A. and Fournier, D. (1997) Molecular forms of acetylcholinesterase from the common oyster (Crassostrea gigas). FEBS Letters, in press.

Bourguet, D., Raymond, M., Fournier, D., Malcolm, C.A., Toutant, J.-P. and Arpagaus, M. (1996a) Existence of two acetylcholinesterases in the mosquito Culex pipiens (Diptera: Culicidae). J Neurochem 67: 2115-2123.
Bourguet, D., Raymond, M., Bisset, J., Pasteur, N. and Arpagaus, M. (1996b) Duplication of the Ace. 1 locus in Culex pipiens mosquitoes from the Carribean. Biochem Genet 34: 351-362.

Bourguet, D., Capela, R. and Raymond, M. (1996c) An insensitive acetylcholinesterase in Culex pipiens (Diptera: Culicidae) from Portugal. J Econ Entomol 89: 1060-1066.

Bourguet, D., Pasteur, N., Bisset, J. and Raymond, M. (1996d) Determination of Ace.1 genotypes in single mosquitoes: toward an ecumenical biochemical test. Pest Biochem Physiol 55: 122-128.

Bourguet, D., Roig, A., Toutant, J.-P. and Arpagaus, M. (1997) Analysis of molecular forms and pharmacological properties of acetylcholinesterase in several mosquito species. Neurochem Int 31: 65-72.

Chatonnet, A. and Lockridge, O. (1989) Comparison of acetylcholinesterase and butyrylcholin-esterase. Biochem J 260: 625-634.

Clements, A.N. (1992) The Biology of Mosquitoes. Chapman and Hall, London.

Cockburn, A.F. and Seawright, J.A. (1988) Techniques for mitochondrial and ribosomal DNA analysis of anopheline mosquitoes. J Am Mosq Control Assoc 4: 261-265.

Corpet, F. (1988) Multiple sequence alignment with hierarchical clustering. Nucl Acids Res 16: 10881.

Cousin, X., Hotelier, T., Lievin, P., Toutant, J.P. and Chatonnet, A. (1996) A cholinesterase genes server (ESTHER): a database of cholinesterase related sequences for multiple alignments, phylogenetic relationship, mutation and structural data retrieval. Nucl Acids Res 24: 132-136.

Eldefrawi, A.T. (1976) The acetylcholine receptor and its interaction with insecticide. Insecticide Biochemistry and Physiology (Wilkinson, C.F., ed.), pp. 297-326. Plenum Press, New York.

Eldefrawi, A.T., Mansour, N. and Eldefrawi, M.E. (1982) Insecticides affecting acetylcholine receptor interactions. Pharmac Theor 16: 45-65.

Ellman, G.L., Courtney, K.D., Andres, V. and Featherstone, R.M. (1961) A new and rapid colorimetric determination of acetylcholinesterase activity. Biochem Pharmacol 7: 88-95.

Felsenstein, J. (1995) PHYLIP (Phylogeny Inference Package), Version 3.57. The author, Department of Genetics, University of Washington, Seattle, Wash.

Fournier, D., Karch, F., Bride, J.M., Hall, L.M.C., Bergé, J.-B. and Spierer, P. (1989) The Drosophila melanogaster acetylcholinesterase gene: structure, evolution and mutations. $\mathrm{J} \mathrm{Mol} \mathrm{Biol}$ 210, 15-22.

Fournier, D., Mutero, A., Pralavorio, M. and Bride, J.M. (1992) Drosophila acetylcholinesterase: analysis of structure and sensitivity to insecticides by in vitro mutagenesis and expression. Multidisciplinary Approaches to Cholinesterase Functions (Schafferman, A. and Velan, B., eds), pp. 75-81. Plenum Press, New York.

Fournier, D. and Mutéro, A. (1994) Modification of acetylcholinesterase as a mechanism of resistance to insecticides. Comp Biochem Physiol 108C: 19-31.

Georghiou, G.P., Metcalf, R.L. and Gidden, F.E. (1966) Carbamate resistance in mosquitoes: selection of Culex fatigans Wied. for resistance to Baygon. Bull WHO 35: 691-708.

Gillies, M.T. and De Meillon, J. (1968) The Anophelinae of Africa South of the Sahara. Publications of the South African Institute for Medical Research, B, No. 54. 
Guptavanij, P. and Barr, A.R. (1979) Plum-eye, a marker for the third linkage group in Culex pipiens (Diptera: Culicidae). J Med Entomol 16: 219-222.

Hall, L.M.C. and Malcolm, C.A. (1991) The acetylcholinesterase gene of Anopheles stephensi. Cell Mol Neurobiol 11: 131-141.

Hall, L.M.C. and Spierer, P. (1986) The Ace locus of Drosophila melanogaster: structural gene for acetylcholinesterase with an unusual 5' leader. EMBO J 5: 2949-2954.

Harbach, R.E., Dahl, C. and White, G.B. (1985) Culex (Culex) pipiens Linnaeus (Diptera: Culicidae): concepts, type designations and description. Proc Entomol Soc Wash 87: 1-24.

Heyse, D., Catalan, J., Nancé, E., Britton-Davidian, J. and Pasteur, N. (1996) Unconventional organization of amplified esterase B gene in insecticide-resistant mosquitoes of the Culex pipiens complex. J Am Mosq Control Assoc 12: 199-205.

Malcolm, C.A. and Hall, L.M.C. (1990) Cloning and characterization of a mosquito acetylcholinesterase gene. Molecular Insect Science (Hagedorn, H.H., Hildebrand, J.G., Kidwell, M.G. and Law, J.H., eds), pp. 57-65. Plenum Press, New York.

Malcolm, C.A., Rooker, S., Edwards, A., Heckel, D. and Hall, L.M.C. (1992) PCR generated homologous DNA probes and sequence for acetylcholinesterase genes in insect pests. Multidisciplinary Approaches to Cholinesterase Functions (Schafferman A. and Velan, B., eds), pp. 87-90. Plenum Press, New York.

Massoulié, J., Pezzementi, L., Bon, S., Krejci, E. and Vallette, F.M. (1993) Molecular and cellular biology of cholinesterases. Prog Neurobiol 41: 31-91.

Miller, B.R., Crabtree, M.B. and Savage, H.M. (1996) Phylogeny of fourteen Culex mosquito species, including the Culex pipiens complex, inferred from the internal transcribed spacers of ribosomal DNA. Insect Molec Biol 5: 93-107.

Mutéro, A., Pralavorio, M., Bride, J.-M. and Fournier, D. (1994). Resistance associated point mutations in insecticide insensitive acetylcholinesterase. Proc Natl Acad Sci USA 91: 5922-5926.

O'Brien, R.D. (1976) Acetylcholinesterase and its inhibition. Insecticide Biochemistry and Physiology (Wilkinson, C.F., ed.), pp. 271-296. Heyden Press, Chichester.

Pan American Health Organisation (1996) Biology and ecology of Anopheles albimanus Wiedmann in Central America. PAHO Technical Paper No. 43.

Pasteur, N. and Raymond, M. (1996) Insecticide resistance genes in mosquitoes: their mutations, migration and selection in field populations. J Hered 87: 444-449.

Perbal, P. (1988) A Practical Guide to Molecular Cloning, 2nd edn. Wiley, New York.

Qiao, C.-L. and Raymond, M. (1995) The same esterase B1 haplotype is amplified in insecticide resistant mosquitoes of the Culex pipiens complex from the Americas and China. Heredity $\mathbf{7 4}$ 339-345.

Rao, T.R. (1984) The Anophelines of India. Malaria Research Centre (ICMR), Delhi.

Raymond, M., Callaghan, A., Fort, P. and Pasteur, N. (1991) Worldwide migration of amplified insecticide resistance genes in mosquitoes. Nature 350: 151-153.

Raymond, M., Pasteur, N., Fournier, D., Cuany, A., Bergé, J. and Magnin, M. (1985) Le gène d'une acetylcholinestérase insensible au propoxur détermine la résistance de Culex pipiens $\mathrm{L}$. à cet insecticide. C R Acad Sci Paris 300(III (14)): 509-512.

Raymond, M., Fournier, D., Bride, J.-M., Cuany, A., Bergé, J.-B., Magnin, M. and Pasteur, N. (1986) Identification of resistance mechanisms in Culex pipiens (Diptera: Culicidae) from south- ern France: insensitive acetylcholinesterase and detoxifying oxidases. J Econ Entomol 79: 1452-1458.

Raymond, M., Pasteur, N. and Georghiou, G.P. (1987) Inheritance of chlorpyrifos resistance in Culex pipiens L. (Diptera: Culicidae) and estimation of the number of genes involved. Heredity $\mathbf{5 8}$ : 351-356.

Raymond, M., Beyssat-Arnaouty, V., Sivasubramanian, N., Mouchès, C., Georghiou, G.P. and Pasteur, N. (1989) Amplification of various esterase B's responsible for organophosphate resistance in Culex mosquitoes. Biochem Genet 27: 417-423.

Raymond, M. and Marquine, M. (1994) Evolution of insecticide resistance in Culex pipiens populations: the Corsican paradox. J Evol Biol 7: 315-337.

Raymond, M. and Pasteur, N. (1996) Evolution of insecticide resistance in the mosquito Culex pipiens: the migration hypothesis of amplified esterase genes. Molecular Genetics and Evolution of Pesticide Resistance (Brown, T.B., ed.), Vol. 645. American Chemical Society, Washington, D.C.

Rousset, F., Bouchon, D., Pintureau, B., Juchault, P. and Solignac, M. (1992) Wolbachia endosymbionts responsible for various alterations of sexuality in arthropods. Proc $R$ Soc Lond B 250: 91-98.

Sambrook, J., Frisch, E.T. and Maniatis, T. (1989) Molecular Cloning: a Laboratory Manual. Cold Spring Harbor Press, New York.

Sutherland, D., McClellan, J.S., Milner, D., Soong, W., Axon, N., Sanders, M., Hester, A., Kao, Y.-H., Poczatek, T., Routt, S. and Pezzementi, L. (1997) Two cholinesterase activities and genes are present in amphioxus. J Exp Zool 277: 213-229.

Swofford, D.L. (1993) PAUP: Phylogenetic Analysis using Parsimony, Version 3.1. Smithsonian Institution, Washington D.C.

Talesa, V.M., Grauso, M., Principato, G.B., Giovanini, E. and Rosi, G. (1995a) Cholinesterase in Helix pomatia (Gastropoda: Stylommatophora): presence of a soluble (hemolymph) and a membrane-bound form. Comp Biochem Physiol 110B: 649656.

Talesa, V.M., Grauso, M., Giovanini, E., Rosi, G. and Toutant, J.-P. (1995b) Solubilization, molecular forms, purification and substrate specificity of two acetylcholinesterases in the medicinal leech (Hirudo medicinalis). Biochem J 306: 687-692.

Taylor, P. (1991) The cholinesterases. J Biol Chem 266: 4025-4028.

Toutant, J.-P. (1989) Insect acetylcholinesterase: catalytic properties, tissue distribution and molecular forms. Prog Neurobio/ 32 : 423-446.

Toutant, J.-P., Massoulié, J. and Bon, S. (1985) Polymorphism of pseudocholinesterase in Torpedo marmorata tissues: comparative study of the catalytic and molecular properties of this enzyme with acetylcholinesterase. J Neurochem 44: 580-592.

Williamson, M.S., Moores, G.D. and Devonshire, A.L. (1992) Altered forms of acetylcholinesterase in insecticide-resistant houseflies (Musca domestica). Multidisciplinary Approaches to Cholinesterase Functions (Shafferman, A. and Velan, B., eds), pp. 83-86. Plenum Press, New York.

Zhu, K.Y. and Clark, J.M. (1995) Cloning and sequencing of a cDNA encoding acetylcholinesterase in Colorado potato beetle, Leptinotarsa decemlineata (Say). Insect Biochem Mol Biol 25: 1129-1138.

Zhu, K.Y., Lee, S.H. and Clark, J.M. (1996) A point mutation of acetylcholinesterase associated with azinphosmethyl resistance and reduced fitness in Colorado potato beetle. Pest Biochem Physio/ 55: 100-108. 